\title{
THE ASSSOCIATIONS BETWEEN ACCREDITATION STATUS, PATIENT SOCIO-ECONOMIC FACTORS, INSURANCE TYPE, PATIENT PERCEIVED QUALITY OF SERVICE, AND SATISFACTION AT COMMUNITY HEALTH CENTER
}

\author{
Farahdila Mirshanti ${ }^{1}$, Didik Gunawan Tamtomo²), Bhisma Murti1 ${ }^{1}$ \\ 1)Masters Program of Public Health, Sebelas Maret University \\ 2)Department of Anatomy, Faculty of Medicine, Sebelas Maret University
}

\begin{abstract}
Background: Being one of the most important elements in healthcare system, Community Health Center has been promoted to improve its quality and capacity of services. Accreditation is a method that can be used to improve and measure the quality of health service. Quality service improvement is expected to enhance patient satisfaction. This study aimed to investigate the asssociations between accreditation status, patient socioeconomic factors, insurance type, patient perceived quality of service, and satisfaction at Community Health Center.

Subjects and Method: This was an analytic observational study with crosssectional design. This study was conducted at Community Health Center in Surakarta, Central Java from June to July 2017. A total of 8 Community Health Centers with different accreditation status (not accredited, lowest, medium, and highest) were selected for this study. A sample of 200 patients were selected from the 8 Comunity Health Centers by proportional random sampling. The independent variables were accreditation status, patient education level, family income, and insurance type. The dependent variables were perceived quality of service and patient satisfaction. The data were collected by a set of pre-tested questionnaires. Accreditation status was identified from the record at District Health Office. Data were analyzed by path analysis.

Results: Patient satisfaction was associated with Commuity Health Center acrreditation status $(b=0.39 ; \mathrm{SE}=0.22 ; \mathrm{p}=0.069)$, perceived quality of service $(b=0.05 ; \mathrm{SE}=0.02 ; \mathrm{p}=0.022)$, patient education level $(\mathrm{b}=-1.16 ; \mathrm{SE}=$ $0.48 ; \mathrm{p}=0.017)$, and insurance type $(\mathrm{b}=0.61 ; \mathrm{SE}=0.31 ; \mathrm{p}=0.044)$. Perceived quality of health services was associated by accreditation status $(b=2.22 ; \mathrm{SE}=$ $0.74 ; \mathrm{p}=0.003)$, patient education level $(\mathrm{b}=-4.51 ; \mathrm{SE}=1.68 ; \mathrm{p}=0.007)$, and insurance type $(b=2.79 ; S E=1.06 ; p=0.008)$. Family income did not show statistically significant association with perceived quality of health service $(b=$ -0.17; $\mathrm{SE}=0.11 ; \mathrm{p}=0.123$ ).

Conclusion: Patient satisfaction is associated with Commuity Health Center acrreditation status, perceived quality of service, patient education level, and insurance type. Perceived quality of health services is associated with accreditation status, patient education level, and insurance type.
\end{abstract}

Keywords: patient satisfaction, perceived quality of service, accreditation status, Commuity Health Center

Correspondence: Farahdila Mirshanti. Masters Program of Public Health, Sebelas Maret University, Jl. Ir. Sutami 36A, Surakarta, Central Java.

Email: fmirshanti@gmail.com. Mobile:+628121534393. 